\title{
A visão Keynesiana sobre decisão sob incerteza: a formação de convenções
}

\section{Resumo}

A incerteza, e o processo de tomada de decisões sob incerteza, são cruciais na visão de Keynes. Como os gestores da riqueza não dispõem de informações objetivas sobre o futuro, eles são obrigados a formar subjetivamente expectativas sobre os acontecimentos e terão necessidade de conferir algum grau de crença àquelas expectativas. Face à incerteza, os agentes econômicos procurarão fixar-se em convenções. Para Keynes, sob incerteza densa, o senso comum premia a convenção contra a ousadia: é melhor errar com a maioria do que acertar contra ela.

\section{Abstract}

The decision-making process under incertitude is crucial in the Keyne's sight. As the wealth mannagers don't dispose of objective information about the future, they are compelled to make subjective expectations about happenings and will need to give some belief to expectations. Face to incertitude, the economic operators will look for settling down conventions. For Keynes, under heavy incertitude, the common-sense rewards the convention against the daring: it's better to make mistake with the most of people than to get success against them.

\section{1 - Introdução}

O Banco Central do Brasil, em meados de janeiro de 1999, após contínua e profunda sangria das reservas brasileiras, resultado da fragilidade dos "fundamentais" da economia, e da crescente perda de credibilidade de sua política cam- bial, depois de tímida tentativa de acalmar o "mercado" com o alargamento da banda (13/01), passa ao regime de câmbio flutuante.

O real despencou.

Os analistas admitem que os agentes econômicos com débitos denominados em dólar, em sua grande maioria, haviam se protegido fazendo algum tipo de hedge.

No dia 21 de janeiro de 1999, o jornal O Estado de São Paulo, entre outros jornais de grande circulação do país, trouxe Nota Oficial do Banco BoaVista.

Nesta, o Banco explicava, como justificativa para as pesadas perdas de seus fundos cambiais depois da desvalorização do real, o funcionamento dos fundos de derivativos, cambiais inclusive, como de perspectiva de retorno elevado, mas com maior risco, visto que atuam com grande agressividade no mercado.

O comunicado acrescentava, ainda, que cada cliente é informado sobre este risco, e que o Banco nada poderia fazer sobre o prejuízo dos aplicadores, pois a regra do jogo seria esta.

No entanto, no mercado, a conversa era outra. Os fundos cambiais do Banco Boa Vista haviam sofrido perdas ao jogar contra o dólar, apostando na continuidade da política do real valorizado, contra a opinião generalizada dos agentes econômicos. A situação, entretanto, era mais complicada, pois a tesouraria do Banco havia atuado no sentido contrário - desvalorização do real - conseguindo um bom lucro. Dias após, o Banco emite novo comunicado permitindo que as posições nos seus fundos fossem fechadas em 14 / 01, portanto, antes da flexibilização cambial. Será que a imagem do Banco ficaria tão desgastada, se os fundos tivessem sofrido as mesmas perdas com apostas no con-

*Mestre em Economia (Demografia Econômica). Bacharel em Ciências Econômicas. Professor das Faculdades Integradas "Campos Salles" e do Centro Universitário UNIFIEO. 
senso do mercado: desvalorização cambial?

Nosso objetivo é, exatamente, examinar a visão Keynesiana, sobre como no mundo incerto dos eventos econômicos - onde o conhecimento não é perfeito, e as probabilidades, se existentes, não são objetivas, nem o mundo é estável e imutável - se dão as ações dos agentes relevantes.

\section{2- A incerteza e a formação de convenções.}

\subsection{A Incerteza}

A incerteza e o processo de tomada de decisões sob incerteza está no âmago da teoria de Keynes.

A visão Keynesiana é discordante em relação à dos clássicos de que a realidade é racional, as probabilidades são objetivas, isto é, o equilíbrio perfeito. Se existisse perfeito conhecimento e fluidez de informação, não haveria razão para que, por exemplo, a Lei de Say não se cumprisse.

Keynes nega a essência clássica: para ele o agente econômico, o empresário produtivo ou financista, tem como mecanismo fundamental de guia de suas decisões, não a busca de alocar fatores, ele busca, isto sim, ampliar riqueza monetária. Na economia Keynesiana, o dinheiro é uma convenção chave, pois é a forma absoluta e geral da riqueza.

Se o objetivo é acumular riqueza em forma de dinheiro, isso pode levar a que a posse de dinheiro tenha prevalência sobre as outras.

A partir daí, como se estrutura o processo de decisão micro e os resultados macro? Como se analisa a conexão entre a natureza das ações econômicas e os resultados? Como é que se configuram os resultados macro, a partir de decisões micro?

A visão Keynesiana está construída na perspectiva de que as estruturas e os resultados econômicos não são dedutíveis axiomaticamente dos processos micro. $\mathrm{Na}$ verdade, os processos macro podem resultar em frustradores das decisões micro.
Dado que os gestores da riqueza não dispõem de informações objetivas, eles são obrigados a formar subjetivamente uma expectativa dos acontecimentos, e mais, eles precisarão conferir algum grau de crença àquelas expectativas. Eles são obrigados a conjecturar sobre as expectativas.

A gestão de riqueza obriga imperiosamente a tomada de decisões. Há que se decidir com base em uma expectativa de futuro, que não pode ser representada por uma probabilidade objetiva, mas sim subjetiva. "Nos casos em que não se pode assinalar de maneira objetiva nenhum valor numérico preciso, é necessário tomar decisões. E, se tomam, como se se pudesse fazer alguma sinalização objetiva de probabilidades; essas probabilidades assinaladas em ausência de conhecimento suficiente poderiam chamar-se 'probabilidades subjetivas'. Estabelecidas com base em conhecimentos insuficientes, estas estariam sujeitas a mudanças rápidas e consideráveis; por isso os processos que obedecem a decisões apoiadas nessa classe de estimações podem mudar tão rápida como bruscamente" (Minsky, 1975).

Sob incerteza densa, os gestores terão que decidir, tomar decisões e, mesmo sabendo que é muito precária a base de decisão, ela não é uma decisão irracional, não o é em termos de propósito: quer acumular; também não o é no que diz respeito a busca de informações e a construção de procedimentos passados e presentes para projetar o futuro. Procedimento racional, embora a decisão em si não seja substantivamente racional. No fundo, suportada no "animal spirits", na crença.

Conforme Keynes: "Não devemos concluir daí que tudo depende de ondas de psicologia irracional. Pelo contrário, o estado de expectativa a longo prazo é, no mais das vezes, estável e, mesmo quando não o seja, os outros fatores exercem seus efeitos compensatórios. O que apenas desejamos lembrar é que as decisões humanas que envolvem o futuro, sejam elas pessoais, políticas ou econômicas, não podem depender da estrita expectativa matemática, uma vez que as bases para realizar semelhantes cálculos não existem e que o nosso impulso inato para a atividade é que faz girar as engrenagens, sendo que a nossa 
inteligência faz o melhor possivel para escolher o melhor que pode haver entre as diversas alternativas, calculando sempre que se pode, mas retraindo-se, muitas vezes, diante do capricho, do sentimento ou do azar."

( Keynes,1985).

Para Keynes, o capitalismo é fadado a acidentes, graves acidentes. O cálculo capitalista é sempre avaliar o valor presente de um negócio futuro, via taxa de juros. Para ele, os juros são uma recompensa pela renúncia à liquidez, e não como queriam os clássicos pela abstenção do consumo.

A taxa de juros intrinsecamente será a taxa básica para avaliar o negócio, será então elemento central no sistema.

Como a taxa de juros não é estável, complica também o cálculo. Mas a decisão central é sempre uma decisão expectacional, convencionada, precária - no sentido de ser uma aventura conjecturada - por isso sujeita a acidentes.

$\mathrm{Na}$ sociedade capitalista, o objetivo fundamental do capital é aumentar a riqueza monetária, busca do lucro em forma monetária.

Mas este processo se faz como um resultado de um conjunto de decisões de agentes não ordenados, até certo ponto independentes, sob incerteza. De tal forma, há uma peculiaridade nesta économia. Como o dinheiro é critério e padrão geral de avaliação de riqueza, em determinados momentos a forma líquida do capital pode vir a ser o eixo principal. A demanda por moeda pode em algum momento polarizar sob a forma mais geral do capital que é a monetária, e criar uma forte preferência pela liquidez.

A determinação da taxa de juros, que é o preço da liquidez, é um fenômeno monetário complexo, porque ela tem de um lado dois componentes: - pode demandar moeda para sua transação comum, mas há um componente da demanda por liquidez, que depende do cálculo com relação ao futuro, e, se este está perturbado, a demanda especulativa por moeda cresce. Para Keynes, especulação é uma conjectura permanente, que faz parte do futuro e que, como todo cálculo do futuro, é especulativo. É um elemento intrínseco da decisão.

Os capitalistas optam pela forma monetária, porque imaginam que outros ativos estão sujeitos à depreciação. Como a moeda não cai nominalmente, então pode servir para proteger o valor monetário de seus ativos.

Por outro lado, para Keynes, o preço da liquidez é formado fora da esfera da produção. Quando se fala em dinheiro, não é simplesmente o conceito M1, mas depósitos a vista e o conjunto de ativos mobilizáveis. A taxa de juros é um processo intimamente ligado à forma do cálculo capitalista. Faz parte deste não só o valor presente do futuro do seu negócio, como também a expectativa com relação à taxa de juros. A preferência pela liquidez é comportamento de autodefesa diante do capital em outras formas.

A economia capitalista é marcada pela transitoriedade e por uma boa dose de indeterminação de trajetórias. Há momentos de ruptura, de indeterminação, ou seja, os estados são transitórios. Não há estados estacionários, o equilíbrio é a exceção.

Para Keynes, a incerteza tem um papel central na gestão do capital, porque, sendo a decisão de gestão fundamentalmente e inevitavelmente baseada num cálculo conjectural a respeito do futuro e sendo o futuro desconhecido, o sistema é obrigado a decidir a respeito da gestão do capital com base em conjectura que lhe permite fazer um cálculo de desconto para o valor presente.

Mas esta conjectura pode estar sujeita a quebra de confiança (todas as decisões são incertas, mas existem as mais incertas que as outras).

A regularidade da sociedade está ligada ao consumo, no entanto, é evidente que, para a variação da renda, conta mais os itens relativos ao investimento fixo e outros tipos de gastos, que são mais oscilantes e mais vulneráveis a acidentes de percurso.

Este problema só pode ser colocado corretamente, se tivermos em mente a existência da moeda enquanto capital. Ou seja, é a forma 
monetária que permite à riqueza transitar de setor, de ambiente.

Mas o dinheiro, enquanto reserva de valor, tem a peculiaridade de não estar sujeito a deflação nominal, como outras formas de liquidez que se revelam mais eficientes e mais convenientes que o dinheiro depósito, que são os títulos públicos de alta confiabilidade.

A essência do fenômeno é procurar uma forma que garanta o valor do principal, buscar um ancoradouro numa situação em que os preços dos ativos estão ameaçados de queda. $\mathrm{O}$ sentido da preferência pela liquidez é proteger o capital.

Isto é básico para o entendimento de que decisões na incerteza podem levar ao abandono dos planos de ampliar seus ativos instrumentais ou liquidar as carteiras de outros ativos que representam riqueza.

\subsection{A formação de convenções}

A formação de expectativa sobre incerteza terá que se basear em outro conceito: convenção.

Ante a incerteza e a premência da decisão, os agentes econômicos recorrem à convenção, admitindo que o hoje é um bom guia para o futuro, o que enfraquece a visão de futuro sujeitando-a a flutuações bruscas e repentinas. Diz Keynes (1985): "Na prática, concordamos, geralmente, em recorrer a um método que é, na verdade, uma convenção. A essência desta convenção - embora ela nem sempre funcione de uma forma tão simples - reside em se supor que a situação existente dos negócios continuará por tempo indefinido, a não ser que tenhamos razões concretas para esperar uma mudança. Isto não quer dizer que, na realidade, acreditemos na duração indefinida do estado atual dos negócios. A vasta experiência ensina que tal hipótese é muito improvável".

A incerteza Keynesiana é típica de uma economia monetária e, em momentos de rupturas de convenções, a moeda é demandada per si.

$\mathrm{O}$ gestor de riqueza terá que convencionar, incorporando o processo social, pois Keynes se recusa a assumir que a decisão é só individual.
Os grupos passam a convencionar determinados resultados. Em estado de incerteza, o gestor da riqueza nem precisa acreditar, mas, como tem que decidir, ele segue uma convenção. $\mathrm{O}$ mercado acredita em determinada convenção, usa-a como critério.

O gestor tem que se cercar de informações, mas ele sabe que nada lhe garante o resultado daquelas probabilidades. Em circunstâncias extremas, a convenção pode levar ao conceito de "mimetismo" que não é irracional. "O mimetismo é o processo chave que permite tornar inteligivel a evolução das necessidades em um sujeito marcado pela inconstância do desejo, por sua indeterminação. Impotente para encontrar em si mesmo uma regra que permita selecionar os produtos, o indivíduo irá voltar-se para os outros, no sentido de buscar orientação para sua busca. Em circunstâncias que privam o indivíduo de todo conhecimento a priori, imitar o outro é a única estratégia racional". ( Anglietta et Orléan, 1990).

Face à incerteza, basta fixar-se em determinadas convenções e, como convenção supõe sociabilização, Keynes abre um outro espaço para formação de grupos de opinião no sistema. Em situações extremas, pode polarizar em uma ou outra direção. Os agentes mais poderosos têm meios para se municiar de informações e, tendo mais meios, tendem a ser formadores de opinião, de convenções. Os agentes de menor porte poderão mimetizar decisões daquele agente maior, decidindo, pelo menos em tese, de melhor forma. Em situações de crise, mimetismo pode ser epidêmico, e com grandes guinadas, ondas ou polarizações.

Dow (1985) coloca com precisão que "Instead, expectations can be treated which each group faces contexts (...) First, since group as well as individual behaviour is an acceptable unit of study, it is possible that expectations formation could be studied separately on a group basis (...) Second, the type of uncertainty which each group faces is different (...) Third, the variables for which expectations are relevant to different groups of decision-markers may be condusive to different forms of modelling, particularly for empirical purposes". 
O cálculo capitalista vai necessariamente passar por determinadas convenções das quais eles não poderão ter conhecimento pleno, dado que não existe por trás soluções ou valores substantivamente verdadeiros. Existe uma grande latitude de soluções, pois expectativas não são homogêneas, e é este conjunto de soluções que estabelecerão soluções de renda. A determinação da renda se dá pelas decisões sob incerteza dos capitalistas, mediadas por expectativas complexas.

Sob incerteza, os capitalistas decidem via convenções, não obstante estas convenções podem ser mutantes. Em condições normais, convenções mais robustas e, em outros momentos, como queria Shackle, caleidoscópia. Isto é, se as "avaliações dependem, no contexto da produção e do investimento, das expectativas. Se as expectativas têm então uma vida própria, se em certo grau elas se originam na imaginação e no pensamento criativo, neste mesmo grau, as avaliações perdem o seu status dependente e se tornam não explicáveis. Expectativas, não derivadas de forma estável e discernivel a partir de outros fatos, tornam-se fontes primárias de eventos, dissolvendo a possibilidade de qualquer futuro determinado". (Shackle, 1972).

Para Keynes, juro é a variável chave para formação de convenções, pois é a ponte que permite o cálculo do capital produtivo e acumulação financeira que permite balizar o custo de carregar em cima de determinado papel, carregar em determinada posição etc.; embora admitisse que, em um país com história de moeda fraca, a taxa de câmbio exerça papel de igual magnitude.

A incerteza cria a necessidade de convenções. A incerteza problematizaria a gestão no sistema. O empresário enquanto gestor precisa decidir. Se o futuro é inteiramente incerto, como decidir? Keynes responde. Se de fato o capitalista tem que decidir em incerteza e não tem um sistema de decisão, é importante que se forme subjetivamente uma expectativa minimamente sociabilizada.

Para ele, será inevitável que os capitalistas criem estratagemas para conviver com a incerteza, adotando determinadas convenções:
- a respeito da taxa de juros;

- a respeito do retorno (projeta o futuro) sobre o investimento, ou eficiência marginal de capital;

- a respeito da taxa de câmbio.

Com relação à decisão de reter uma parte do capital sob a forma de reserva financeira que não vai ser investida imediatamente, terá que se convencionar uma expectativa a respeito de valorização dos ativos financeiros. Preços destes ativos são mais voláteis do que dos ativos instrumentais, embora a volatilidade não seja tão importante quanto a tendência.

Essa necessidade de formar convenções envolve elementos de racionalidade, mas é uma construção subjetiva. Em Keynes, cálculo capitalista não é individual, há um certo grau de socialização, não sendo homogênea, é uma distribuição subjetiva. Neste sentido são probabilidades subjetivas, mas estas têm um certo grau de confiança.

No entanto, não existem funções únicas iguais para todos os grupos de agentes. Se tomar uma expectativa sobre a qual é preciso que se forme uma percepção geral, não uma específica de um setor ou de uma categoria, pode haver percepções diferentes e divergentes.

$\mathrm{O}$ que diferencia a incerteza Keynesiana da visão convencional, é que nesta só existe uma única distribuição de probabilidades, não existindo viés, a distribuição é estocástica. A incerteza Keynesiana é totalmente diferente. Nenhuma é confiável para ser estável, mas elas podem ser mutáveis, aliás, freqüentemente estão mudando.

A confiabilidade na margem, sendo crescente, pode dar origem, ainda que exista uma variança maior, a uma convenção para taxa de juros ou taxa de câmbio. Se estas probabilidades se estabilizam, aquele estado pode se repetir, o que não quer dizer que para Keynes não possa mudar ( $\mathrm{O}$ capitalismo é um sistema que funciona bem, mas pode não funcionar!).

Há um estado de confiança, de que as coisas se reproduzem dando uma aparência de ergocidade. As expectativas podem convergir. Mas pode haver outro estágio de incerteza ativa, tem-se uma 
distribuição de probabilidade, mas as probabilidades de segunda ordem são erráticas, ora no sentido de melhorar, ora de piorar. Ou existe uma dificuldade de fixar uma convenção ou a convenção anterior começa a ficar fragilizada; se a anterior já explodiu, fica difícil formar outra.

Função subjetiva que vai ficando precária, há um estado de incerteza ativa que mostra que as convenções são efêmeras. A lógica da gestão sobre incerteza é essa busca de convenção. Mas nesta incerteza ativa, ou tensa, torna-se impossível para os agentes formarem uma nova convenção, levando a um estágio de insegurança geral e que tende a criar formas de fuga ou busca de refúgio da garantia do capital. Estágio que explica fuga, aversão radical ao padrão monetário ou uma fuga coletiva dos ativos de riqueza, levando a uma deflação muito aguda dos ativos. São estágios de fuga coletiva - raros- mas nãı tão suficientemente raros que possa ser dito que são insuficientes.

Para Keynes, é racional formar convenções otimistas ou pessimistas. É melhor aderir a convenções, mesmo que não se tenha muita certeza, são estas adesões às convenções que permitem, mesmo na crise, algumas previsões.

$\mathrm{Na}$ visão Keynesiana, a racionalidade tem a dimensão processual, isto é, conhecimento perfeito não é possível, a racionalidade sendo necessária para a decisão capitalista ( cálculo conjectural vai buscar equalizar a taxa ideal de retorno entre as diversas opções de gestão de ativos) exige uma racionalidade de cálculo para fazer a conjectura.

"O determinismo foi, desta forma, claramente rejeitado para a economia, assim como para as demais áreas das ciências humanas. Paralelamente, Keynes esboçou uma teoria muito moderna da causalidade probabilística. A racionalidade substantiva foi também rejeitada, pois, em situações de forte incerteza, qualquer cálculo de custos e benefícios, por mais sofisticado que fosse, seria impossivel ou não confiável. Admitia-se, portanto, o papel dos impulsos aparentemente irracionais nas decisões humanas, desde a influência da alquimia e do eso- terismo nos pensamentos de Newton, até o impacto dos "animal spirits" dos empresários sobre as decisões de investimento" (Vercelli, 1994).

Num estado de incerteza, abre-se a possibilidade de que agentes procurem induzir o comportamento de outros, racionalidade criativa que dá origem a especulação em que os agentes são optims makers. Os agentes, pelo seu peso e capacidade de arrastar outros, podem influir além de uma racionalidade procedural, manipulando informações.

Belluzo e Coutinho (1996), ao examinarem as transformações financeiras globais, levantam este ponto: "É ingenuidade supor que este mercado atenda aos requisitos de eficiência, no sentido de que não possam existir estratégias 'ganhadoras' acima da média, derivadas de assimetrias de informação e de poder. Os protagonistas relevantes nestes mercados são, na verdade, os grandes bancos, os fundos mútuos e a tesouraria de grandes empresas que decidiram ampliar a participação da riqueza financeira em seu portfólio. Em condições de incerteza radical, estes agentes são obrigados a formular estratégias com base em uma avaliação 'convencionada' sobre o comportamento dos preços. Dotados de grande poder financeiro e de influência sobre a opinião dos mercados, eles são na verdade formadores de convenções, no sentido de que podem manter, exacerbar ou inverter tendências. Suas estratégias são mimetizadas pelos investidores com menor poder e informação, ensejando a formação de bolhas altistas e de colapsos de preços."

Shackle (1991), na sua interpretação - um pouco particular e bem psicológica - da visão Keynesiana da incerteza e formação de convenções, admite que "se toda a iniciativa é sustentada apenas pela expectativa, e toda expectativa é uma mera conjectura ou invenção sobre algo (isto é, o futuro) que, na natureza das coisas, não pode ser observada e que, portanto, não pode ser objeto de qualquer conhecimento real, o que é que pode emprestar uma aparência de estabilidade e consistência, mesmo a curto prazo, à conduta dos negócios? A sua resposta é que os homens desejam e, portanto, assumem a realidade e o significado de 
alguma "normalidade". Eles atribuem alguma autoridade ao que é. Eles assumem que, em algum grau, as coisas continuarão como estão, ou como elas foram grosso modo no passado, em pelo menos alguns poucos aspectos fundamentais. Existe uma convenção tácita e instintiva em se acreditar na justeza e no poder de reafirmação das coisas, tal como eles a conheceram em suas linhas gerais. (...) A noção de um estado de expectativas, que pode ser suposto imutável por um certo intervalo de tempo ou de eventos, mas que é essencialmente frágil 'e radicalmente mutável, a partir de fontes inumeráveis que ninguém pode prever, é a sua versão especial de ceteris paribus."

\section{3 - Conclusão}

E o Banco BoaVista?

Além de ter recuado naquele intento inicial de jogar "preto no branco" e deixar o mico com seus cotistas, existiram comentários de que o prejuízo para sua imagem fora tão grande, a repercussão dos episódios referidos tão negativa, que se levantou a hipótese de mudança de nome, para fugir ao estigma. Finalmente, em agosto de 2.000, o Banco foi vendido para o Bradesco/BCN.

Keynes (1985) também chamou atenção sobre a hipótese do agente econômico trabalhar contra o convencional : "se obtém êxito, isto apenas confirmará a crença geral na sua temeridade; se, no final de contas, sofre reveses momentâneos, poucos serão os que dele se compadecerão. A sabedoria universal indica ser melhor para a reputação fracassar junto com o mercado do que vencer contra ele."

Dada a incerteza, inerente às expectativas quanto ao futuro, há um custo e um perigo de se proceder de forma diversa ao comumente aceito, isto é, contra a convenção.

\section{REFERÊNCIAS BIBLIOGRÁFICAS}

ANGLIETTA, M.; ORLÉAN, A. A violência da moeda. São Paulo: Brasiliense, 1990.

BELLUZO, L. G.;COUTINHO, L. G. Desenvolvimento e estabilização sob finanças globalizadas. In: Economia e Sociedade . Campinas: Unicamp, n. 7. dez. 1996.

DILLARD, D. A teoria econômica de John Maynard Kéynes. São Paulo: Biblioteca Pioneira de Ciências Socias, 1993.

DOW, S. Macroeconomic Thought. Oxford, England: Basil Black Well Ltd.,1985.

KEYNES, J. M. A Teoria Geral do emprego, do juro e da moeda. São Paulo: Nova Cultural, 1985.

MINSKY, H. P. John Maynard Keynes. New York: Columbia University Press, 1975.

SHACKLE, G. L. S. Epistemics and Economics. Cambridge: University Press, 1972.

Origens da Economia Contemporânea. São Paulo Hucitec, 1991.

VERCELLI, A. Por uma Macroeconomia não reducionista : uma perspectiva de longo prazo. In. Economia e Sociedade. Campinas: Unicamp, n. 3, dez. 1994. 